\title{
Case Report \\ Lung Cancer Presenting as Acrometastasis to the Finger: A Case Report
}

\section{Lawrence Stephen Long, ${ }^{1}$ Leslea Brickner, ${ }^{1}$ Lisa Helfend, ${ }^{2}$ Tony Wong, ${ }^{1}$ and Derek Kubota ${ }^{3}$}

${ }^{1}$ Department of Medicine, Kaiser Permanente, Oakland, CA 94611, USA

${ }^{2}$ Department of Pathology, Kaiser Permanente, Oakland, CA 94611, USA

${ }^{3}$ Department of Radiology, Kaiser Permanente, Oakland, CA 94611, USA

Correspondence should be addressed to Lawrence Stephen Long, 1.stephen.long@gmail.com

Received 24 March 2010; Accepted 15 May 2010

Academic Editor: Carol Lally Shields

Copyright (C) 2010 Lawrence Stephen Long et al. This is an open access article distributed under the Creative Commons Attribution License, which permits unrestricted use, distribution, and reproduction in any medium, provided the original work is properly cited.

\begin{abstract}
Lung cancer is the commonest cause of acrometastatic disease to the fingers. Here we describe a case of occult lung cancer presenting as unrelenting finger pain and swelling from a metastatic phalangeal fracture. The patient's management was largely palliative and he died soon after discovery of the primary tumor. Digital acrometastatic disease rarely becomes symptomatic before the primary lung cancer is diagnosed and, as observed in this case, carries a very poor prognosis. Clinicians should be cognizant of the strong association between digital acrometastases and bronchogenic carcinoma and vigilant in screening high-risk patients with importunate finger symptoms.
\end{abstract}

\section{Introduction}

The bones of the finger rarely harbor metastatic disease, but when they do, it is a revealing clinical finding. Most bony metastases, including nondigital acrometastatic disease, arise from a wide array of primary tumors (e.g., prostate, lung, kidney, breast, gastrointestinal). By contrast, the etiology of digital acrometastases is almost exclusively bronchogenic carcinoma [1]. Fortunately, digital acrometastatic lung cancer is seldom seen, accounting for approximately one out of 500 lung cancers with bony metastases [2]. It carries a grim prognosis, with a mean survival of three to six months after presentation $[3,4]$.

Here we describe a case of occult lung cancer presenting as metastatic disease to the finger.

\section{Case Presentation}

A 53-year-old Guamanian-American man with seven packyears of smoking, asbestos exposure as a child, and a family history of lung cancer suffered from a swollen, erythematous, painful tip of the left third finger. He first blamed the swelling on an embedded splinter, which he quickly dislodged with warm compresses and tweezers. However, the swelling persisted and the erythema deepened (see Figure 1). After two months of unremitting finger pain, he developed right hip pain subsequent to falling off a ladder. His primary care physician attributed the finger and hip pain to trauma, prescribed etodolac, and ordered a radiograph of the hip, which was unremarkable.

Two weeks later, the patient presented to the emergency department with sudden-onset chest pain, exacerbated by deep breathing. He was tachypneic, tachycardic, and slightly hypoxic. Computed tomography revealed a right upper lobe lung mass and right hilar adenopathy. Poorly differentiated adenosquamous carcinoma, characterized by positivity to mucin, CK7, TTF1, P63, and CK5/6, was seen on lung pathology.

The patient received high-dose intravenous narcotics but nonetheless reported persistent finger pain. Orthopedics was consulted. Two radiographic views of the left hand showed a highly aggressive lytic lesion involving the distal phalanx with permeative margins and slight immature periosteal reaction. There was significant associated soft tissue swelling or mass, as well as an associated minimally displaced pathologic fracture through the midportion of the phalanx. 


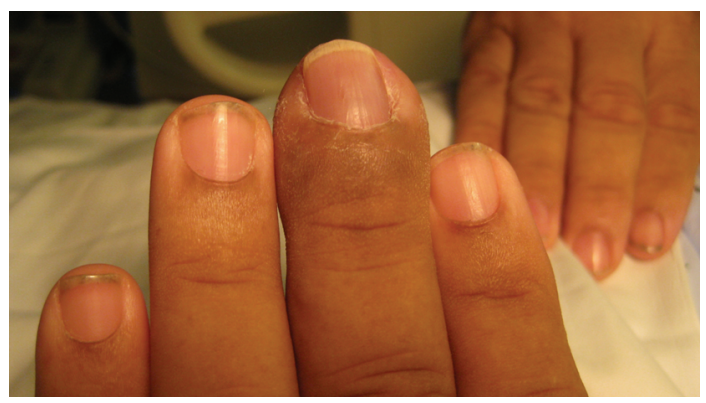

Figure 1: A swollen, painful tip of the left third finger.

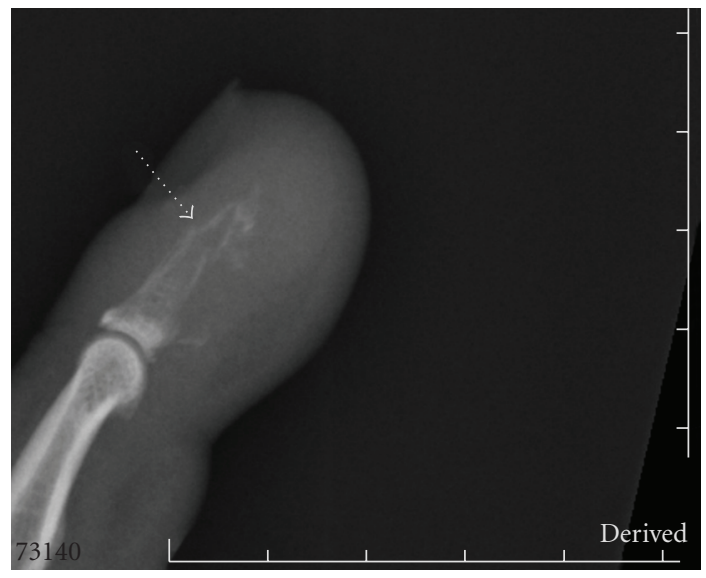

FIgUre 2: A pathologic fracture of the distal phalanx.

Additionally, there were adjacent tiny ossific or calcific fragments, possibly displaced bony fragments or dystrophic soft tissue calcification (see Figure 2). Taken together, the radiographic findings argued strongly against a traumatic injury, but instead supported a destructive and infiltrating process, such as lytic metastasis. The patient declined biopsy, elected comfort measures only, and died one month later.

\section{Discussion}

Acrometastasis is reported infrequently, with only one out of 1000 bony metastases traveling to the hand [5]. The primary tumors most implicated, in order of prevalence, are lung, kidney, breast, and gastrointestinal [4]. Men are more likely to be affected than women, with solitary phalangeal lesions commonly observed [4].

The tumor cells are thought to migrate to the bones of the hand via blood, not lymphatics [6]. Although the wide hematogenous spread of many visceral organ tumors is often restricted by the hepatic and pulmonary capillary beds, malignant cells of the lung have unimpeded access to the distal arterial system. This may explain why the commonest source of acrometastic disease is bronchogentaic carcinoma [6].

While acrometastatic lung cancer is rare, occult lung cancer presenting as metastasis to the finger is even more exceptional. Although good epidemiologic data for lung cancer are unavailable, one small study found that approximately $10 \%$ of acrometastases became symptomatic before the primary tumor was identified [7].

The presentation of digital acrometastatic lesions varies. The affected finger may appear infected, with tenderness, erythema, heat, and swelling [8]. In addition, the overlying skin may weep, bleed, or ulcerate $[3,9]$. Terminal phalanges of the dominant hand are most commonly involved $[4,10]$.

Importantly, bronchogenic metastases to bone are usually lytic in nature [4]. Although the current case did not have a biopsy-proven acrometastatic lesion, radiographic differential considerations were narrow and supported an aggressive lytic metastasis to bone in a patient with known lung cancer. Nonetheless, another process, such as acute osteomyelitis or primary neoplasm, could not be excluded without biopsy.

As seen in this case, patients may report a history of trauma to the affected finger. Interestingly, some authors argue that a history of trauma is causal, not coincident, by introducing malignant cells to the bone through increased blood flow and the release of local chemotactic factors [11]. These factors, including prostaglandins, promote cell migration and adhesion to bone, and may create a conduit for metastatic disease.

Given the bleak prognosis of digital acrometastatic lung cancer, treatment is largely palliative. Amputation and chemotherapy have been used, but recent literature suggests that localized radiotherapy can successfully relieve pain and return function to the affected finger [4]. There may also be a targeted role for bone-remodeling pharmacotherapies, such as bisphosphonates or denosumab, which have demonstrated utility in treating other bony metastases $[12,13]$.

As this case illustrates, clinicians must be mindful in screening patients at risk for lung cancer with persistent digital symptoms.

\section{References}

[1] C. M. Galmarini, A. Kertesz, R. Oliva, J. Porta, and F. C. Galmarini, "Metastasis of bronchogenic carcinoma to the thumb," Medical Oncology, vol. 15, no. 4, pp. 282-285, 1998.

[2] P. P. Kumar, "Metastases to the bones of the hand," Journal of the National Medical Association, vol. 67, no. 4, pp. 275-276, 1975.

[3] M. Heidarpour, P. Rajabi, A. Eftekhari, and H. R. Ghasemibasir, "Lung carcinoma metastasis to the distal part of the index finger: a case report," Iran Journal of Pathology, vol. 1, pp. 173-176, 2006.

[4] C. J. Flynn, C. Danjoux, J. Wong, M. Christakis, J. Rubenstein, A. Yee, D. Yip, and E. Chow, "Two cases of acrometastasis to the hands and review of the literature," Current Oncology, vol. 15, no. 5, pp. 51-58, 2008.

[5] R. Kerin, "Metastatic tumors of the hand. A review of the literature," Journal of Bone and Joint Surgery. Series A, vol. 65, no. 9, pp. 1331-1335, 1983.

[6] G. Asencio, CH. Hafdi, H. Pujol, and Y. Allieu, "Osseous metastases in the hand. A general review of three cases," Annales de Chirurgie de la Main, vol. 1, no. 2, pp. 137-145, 1982. 
[7] R. Baran, P. Guillot, and A. Tosti, "Metastasis from carcinoma of the bronchus to the distal aspect of two digits," British Journal of Dermatology, vol. 138, no. 4, p. 708, 1998.

[8] N. Khokhar and J. D. Lee, "Phalangeal metastasis: first clinical sign of bronchogenic carcinoma," Southern Medical Journal, vol. 76, no. 7, p. 927, 1983.

[9] H. Nakamura, T. Shimizu, K. Kodama, and H. Shimizu, "Metastasis of lung cancer to the finger: a report of two cases," International Journal of Dermatology, vol. 44, no. 1, pp. 47-49, 2005.

[10] R. Kerin, "The hand in metastatic disease," Journal of Hand Surgery, vol. 12, no. 1, pp. 77-83, 1987.

[11] E. T. Tolo, W. P. Cooney, and D. E. Wenger, "Renal cell carcinoma with metastases to the triquetrum: case report," Journal of Hand Surgery, vol. 27, no. 5, pp. 876-881, 2002.

[12] N. Pavlakis, R. Schmidt, and M. Stockler, "Bisphosphonates for breast cancer," Cochrane Database of Systematic Reviews, no. 3, Article ID CD003474, 2005.

[13] M. R. Smith, B. Egerdie, N. Hernández, R. Feldman, T. L. J. Tammela, F. Saad, J. Heracek, M. Szwedowski, C. Ke, A. Kupic, B. Z. Leder, and C. Gossl, "Denosumab in men receiving androgen-deprivation therapy for prostate cancer," New England Journal of Medicine, vol. 361, no. 8, pp. 745-755, 2009. 


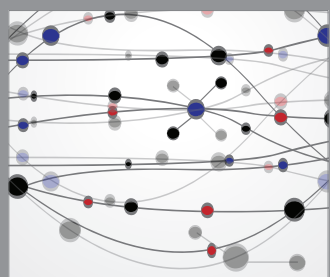

The Scientific World Journal
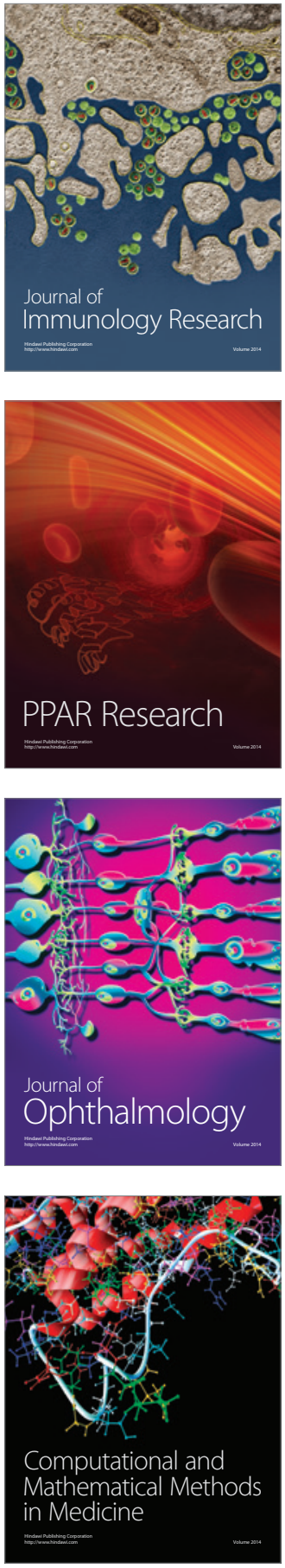



Gastroenterology

Research and Practice
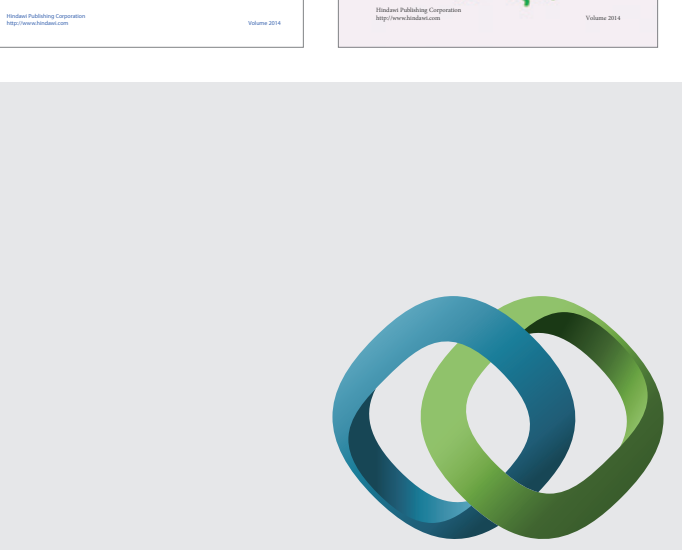

\section{Hindawi}

Submit your manuscripts at

http://www.hindawi.com
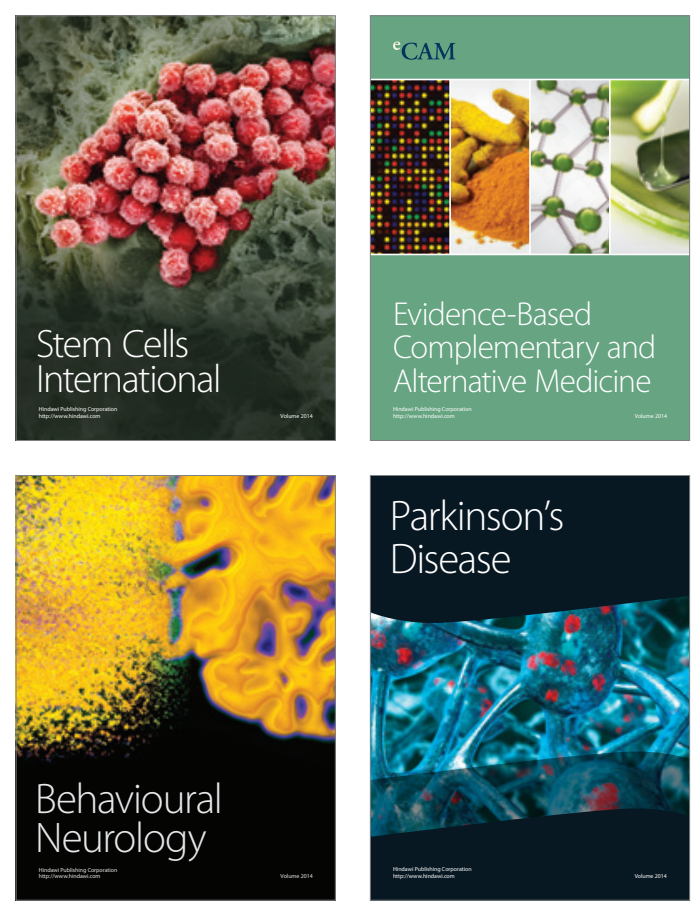

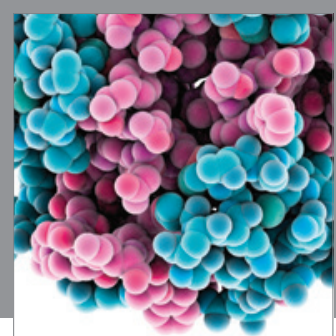

Journal of
Diabetes Research

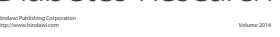

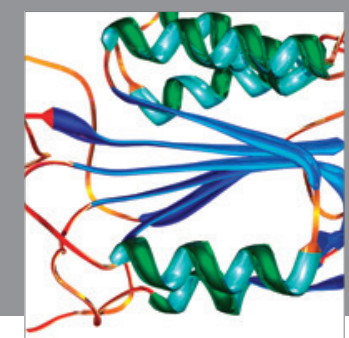

Disease Markers
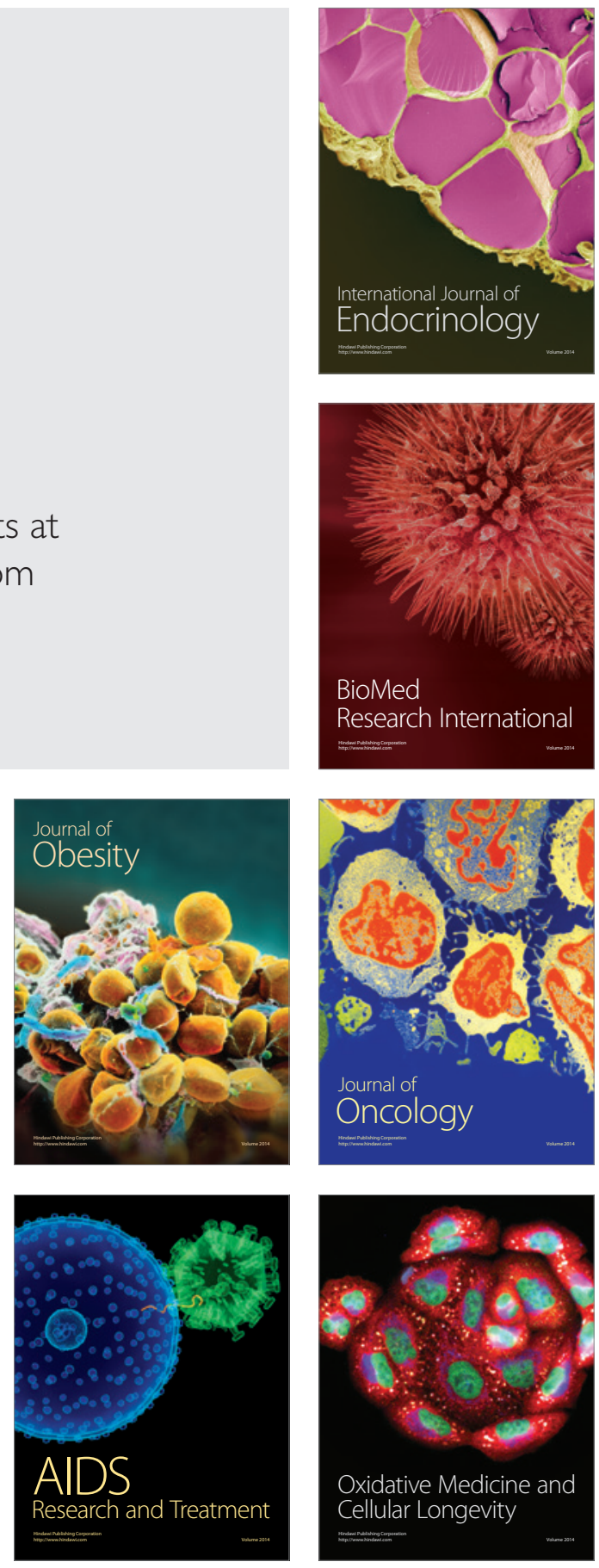